\title{
Energy Saving in the Pharmaceutical Industry
}

\author{
Aviraj Madke \\ M-Tech Student,Department of Mechanical Engineering, Priyadarshini College of Engineering, Nagpur, \\ Maharashtra, 440019. E-mail: madkeaviraj@gmail.com
}

\begin{abstract}
This study describes the role of energy performance benchmarking in the pharmaceutical industry, explains why large variations in building performance exist and how to use benchmarking data to drive meaningful results into a successful energy management program.
\end{abstract}

Keywords- Space Conditioning, HVAC, Lighting, Facilities.

\section{I- INTRODUCTION}

$\mathbf{Y}_{\text {ou }}$ ou can't manage what you can't measure. This axiomatic statement holds true in all aspects of life; it is hard to manage one's weight without a scale and it's hard to manage how fast one is traveling without a speedometer. Like- wise, it is hard to manage the energy performance of a building without a similar macro-level indicating gauge. There is no better way to assess the overall performance of a building than to compare it to other buildings similar inform, function, and location. Unfortunately, this is frequently an acutely difficult task to perform in the pharmaceutical sector. While tools for this evaluation do exist, they are not without their limitations as the approach for comparison is sometimes over-generalized. Facility design and layout play a dramatic part in the overall utility consumption of a facility as, unlike in the commercial sector, the majority of the energy consumption in pharmaceutical manufacturing buildings lies within the process itself and the systems that support it. Several examples will be presented to show just how profound the differences in energy consumption can be. This article will describe the role of energy performance benchmarking in the pharmaceutical industry, explain why large variations in building performance exist and how to use benchmarking data to drive meaningful results into a successful energy management program.

\section{II - METHODS}

\subsection{Commercial Building Benchmarking}

In the commercial building realm, there are extensive resources available that make this data available for all to use. The Commercial Building Energy Consumption Survey (CBECS), managed by the U.S. Energy Information Ad- ministration under the Department of Energy (DOE), has collected and analysed data for many different types of commercial buildings. The CBECS database is the most robust resource currently available, not only from the quantity of buildings in the survey, but from the vast number of ways that the data has been sliced and diced for comparative purposes as well.

The CBECS is a national survey that collects information on the stock of United States commercial buildings including energy related building characteristics, energy consumption, and expenditures. The buildings in the study incorporate all buildings in which at least half of the floor space is used for a purpose that is not residential, industrial, or agricultural. The survey includes building types that might not tradition- ally be considered commercial, such as schools, correctional institutions, and buildings 


\section{International Journal of Innovations in Engineering and Science, www.ijies.net}

used for religious worship.

The CBECS database has had several setbacks in recent years with the 2007 survey information being thrown out due to insufficient survey methods and the 2011 survey being cancelled due to funding cuts. Fortunately, funding has since been garnered and work on updating the survey for 2012 has recently begun. Regardless of its flaws, the CBECS database remains the best source of reliable information to bench- mark the energy performance of a commercial building. [1]

It is upon this premise that the Environmental Protection Agency's (EPA) Energy Star building performance rating system has been built upon. Using the information in the CBECS database, energy performance indicator tools exist that allow users to input simple statistics regarding building size, type, location, occupancy and overall utility consumption in exchange for a 1-100 percentile rating that benchmarks the performance of the user's building against similar buildings. Buildings scoring in the 75th percentile or higher are eligible for the Energy Star certification. The tool com- pares the inputted building criteria to a normalized model to adjust for inconsistencies in form, function, and location based on the CBECS database.

Commercial buildings have a common bond in their primary function in that they are designed primarily to maintain the comfort of the occupants. Lighting and space conditioning (heating, ventilation and air conditioning) energy consumption are relatively similar and vary predictably with only a few variables. Based upon the EIA Annual Energy Outlook 2012, lighting and space conditioning account for $13.6 \%$ and $47.3 \%$ respectively $(60.9 \%$ combined $)$ of the total building energy consumption footprint. 2 The remaining consumption is allocated between various plug loads and water heating requirements as shown in Figure 1.

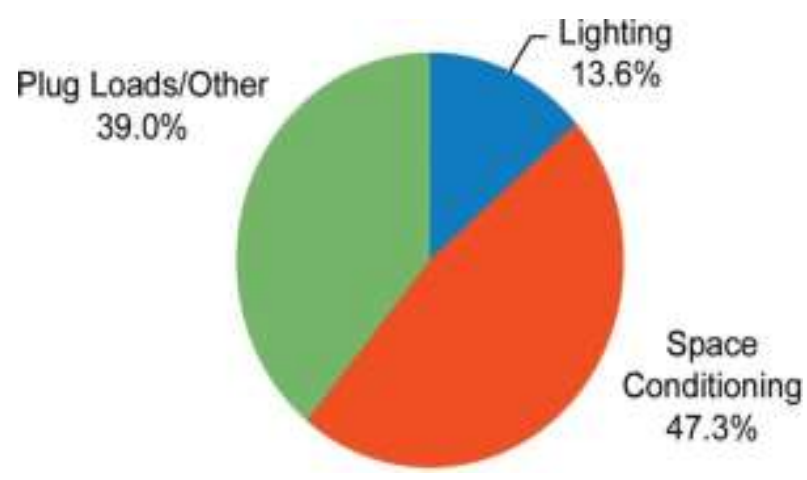

Fig 1- Commercial building energy consumption by end use.

Since the majority of the commercial building energy consumption is dedicated to lighting and environmental comfort systems, the Energy Star tool needs only to prompt the user for a small number of inputs to be able to quickly normalize the subject building to the model and develop a highly reliable energy performance benchmark.

\subsection{Pharmaceutical Building Benchmarking}

Moving out of the commercial building realm into the industrial and manufacturing building classes, a problem arises. In general manufacturing, energy is also consumed to con- duct whatever processes are required to make the product. This consumption frequently goes beyond just powering the production equipment itself; it also encompasses increased base building utility system requirements from additional or more stringent HVAC requirements to greater lighting intensity requirements to additional utilities such as compressed air, vacuum systems, etc. It is this manufacturing energy consumption that is highly variable and difficult to normalize within a benchmarking model. This problem is exacerbated in the pharmaceutical industry due to the need to maintain critical environments for production with respect to temperature, humidity, room pressurization, cleanliness, containment, and other contributing factors. Building HVAC loads are many times greater than the average commercial building to support these processes. As a result, overall building Energy Usage Intensity (EUI) is typically an order of magnitude larger or more. The average recently built (after 2000) commercial office building has an average EUI of 81.4 $\mathrm{kBtu} / \mathrm{sq}$. ft. (257 kWh/m2). [3]

The average pharmaceutical plant has an EUI of $1,210 \mathrm{kBtu} / \mathrm{sq}$. ft. $(3,819 \mathrm{kWh} / \mathrm{m} 2) .4$ Contributing factors to these relatively higher levels in building HVAC loads compared to general commercial buildings include, but are not limited to, the following:

- Increased airflow quantity requirements

- Increased ventilation requirements

- Increased filtration requirements

- Requirements for tighter environmental controls (temperature and humidity)

The above factors lead to higher energy consumption through increased:

- Cooling loads

- Preheat loads

- Reheat loads

- Fan energy consumption

- Dehumidification/humidification loads 


\section{International Journal of Innovations in Engineering and Science, www.ijies.net}

Discussion regarding the quantification and analysis of the causes for increased consumption is a study in itself andis often cumbersome to calculate. For simple comparative purposes however, consider that a standard air handling unit serving an office area is going to condition and supply between two to six Air Changes Per Hour (ACPH) to the space in a variable air volume control strategy. An analogous air handling unit serving an ISO 14644-1:1999 class 8 (EU Grade C in operation) cleanroom in which pharmaceutical product is being manufactured would typically condition and supply between 20 and 35 ACPH to the cleanroom in a constant volume control strategy. This represents approximately a four to six-fold increase in HVAC energy expenditure before tighter temperature and relative humidity control requirements, increased outside air requirements, and additional filtration are considered. With the additional energy consumption of the manufacturing systems and processes themselves, it can easily be seen how the overall energy consumption of pharmaceutical facilities becomes far more intensive than their commercial facility counterparts.

Based on the unique nature of the industry and the in- ability of existing tools to effectively gauge the performance of these buildings, the EPA Energy Star program developed a meaningful comparative tool uniquely dedicated to benchmarking energy consumption in the pharmaceutical industry. Led primarily by energy managers from several major drug manufacturers, the Energy Star program began a pharmaceutical industry focus early in 2005.5 From those initial efforts, the first version of the pharmaceutical industry Energy Performance Indicator (EPI) tool was developed and published at the end of 2008. Last updated in the summer of 2012, the tool seeks to normalize and benchmark facility energy performance of facilities located in the United States across three major categories:

- Bulk Chemical (Active Pharmaceutical Ingredients and Excipients) - areas where both active and inactive

- ingredients are prepared in bulk form, including mixing, milling and drying of powders, and the mixing of liquids, gels and creams. [6]

- Fill/Finish - all areas used for fill or finish processes or other manufacturing, production or warehousing with climate controlled environments due to product requirements. Fill/finish includes tableting, encapsulation of powders or liquids, the final packaging of the product and the filling of liquids, gels or creams in their consumer packages. [6]

- Research and Development - laboratory buildings including animal labs, storage space, in process labs, QA labs and pilot plants.6

- Other final category dedicated to any area that does not fall into any of the above main categories.[6]

Since data regarding space allocation in the above categories is not collected in the Census of Manufacturers, data had to be provided directly from participating entities within the program. [7] Similar to the commercial buildings program, the pharmaceutical EPI takes several inputs regarding percent- age of facility floor space allocated to the above functions, hours of operation, location, and utility costs and in return will provide a 1 to 100 percentile rating for the facility. This tool also now provides the EPA with a benchmarking tool to grant the Energy Star rating to facilities scoring in the 75th percentile or above, which was not previously possible.

\subsection{Variations in Benchmarking Data}

When the EPA initiated discussions about developing a plant level benchmarking tool with pharmaceutical manufacturers, most initial reactions from experts within these companies were sceptical about whether a useful benchmark could be developed. The typical approach for the development of EPI's for other industries is to relate plant input to plant output as expressed as a unit of production. The pharmaceutical EPI does not. It was decided that the value of product shipments would not provide a uniform measure of activity since, as discussed above, while the level of production isnot insignificant, much of the energy use in this industry isdevoted to environmental control. [7]

Those involved in the development of the tool self admittedly state that normalization of all facilities against the three categories allocated may not be entirely appropriate. Specifically recommended in this article is the development of additional categories in accordance with the ISPE Baseline ${ }^{\circledR}$ Guides at a minimum. As a particular example, separate categories should be developed to differentiate the large energy consumption differences that exist between oral solid dose form, aseptic processing, and biopharmaceutical processing. The good engineering practices that govern the design of these types of manufacturing processes are vastly different. Yet, under the current model, these processes are all grouped together.

Even among the subsets of different aspects of 


\section{International Journal of Innovations in Engineering and Science, www.ijies.net}

pharmaceutical processing as laid out in the ISPE Baseline ${ }^{\circledR}$ Guides, certain design factors will drastically affect the energy consumption from one facility to the next. For example, cross-contamination concerns at an oral solid dosage facility handling multiple products may encourage the HVAC system designer to utilize $100 \%$ outdoor air, whereas a single product facility may utilize a recirculation HVAC system using supplemental filtration to minimize the risk of airborne crosscontamination. The energy consumption impact of $100 \%$ once through systems versus a recirculation system can be as much as three times.

Similarly, consider the various cleanroom contamination containment control technologies used in aseptic/sterile processing. Assume the following air change design criteria for this analysis:

- Unidirectional airflow ISO 5 (in operation) / EU Grade A300 - 600 ACPH

- Non-unidirectional airflow ISO 7 / EU Grade B - 60 $\mathrm{ACPH}$

- Non-unidirectional airflow ISO 8 / EU Grade C - 30 $\mathrm{ACPH}$

- Non-unidirectional airflow controlled unclassified $15 \mathrm{ACPH}$

The design criteria listed above assumes a conventional recirculation type HVAC system with no unoccupied/silent hour airflow or temperature/humidity setbacks. A vial filling suite using a Restricted Access Barrier System (RABS) re- quires ISO 5 (in operation) (EU Grade A) conditions within the RABS in an ISO 7 (in operation)/ Grade B background as shown in Figure 2.

The same vial filling suite utilizing isolator technology instead of a RABS reduces the suite classification requirement to an ISO 8 (in operation)/ Grade C background (note that EU would allow a Grade D background). In addition, the ISO 5 (in operation) environment is completely contained with the microenvironment within the isolator as seen in Figure 3.

Analysis of the different containment technologies shows a $30-50 \%$ energy savings using isolators versus RABS technologies within the HVAC systems serving the filling suites themselves. Based on the dataset gathered for the pharmaceutical EPI tool, the meanfacility is $27 \%$ bulk chemical (API and excipient), $20 \%$ fill/finish and $10 \%$ research and development by space allocation. The remaining $43 \%$ is classified in the other designation. The median facility EUI is 1,391 $\mathrm{kBtu} / \mathrm{sq}$.ft. $(4,391 \mathrm{kWh} / \mathrm{m} 2)$ (50th percentile rating). The score needed to qualify for Energy Star (75th percentile) is $806 \mathrm{kBtu} / \mathrm{sq}$.ft. $(2,544 \mathrm{kWh} / \mathrm{m} 2) .4$ The main purpose of the examples presented is to show that oncethe facility is designed, the energy performance is largely locked in and significant variations can exist. Therefore, it comes into question what the benchmarking data is actually showing; is a 75th percentile score depicting the performance of buildings that display significant energy management best practices or is it simply a result of the inherent facility design driven by less stringent process requirements?

\subsection{Making a Meaningful Impact to Facility Energy Reductions}

Perhaps it is best to answer a question with another question; does it matter? While the type of facility being analyzed may be precluded from ultimately achieving an Energy Star certification, the better use of the EPI tool is to use it as a gauge to measure a facility's ongoing energy management strategies over time. A reduction in annual score in an otherwise unchanged building may hint that a tune up is needed via retro-commissioning. The average pharmaceutical facility would need to reduce overall energy consumption by a third to reach the Energy Star threshold; the equivalent of the total EUI of five commercial office buildings of equal size.

While such a task may seem daunting at the onset, most pharmaceutical entities have aggressive internal mandates to reduce energy expenditure year over year. With the cur- rent downward pressure on internal costs, a $5 \%$ target reduction annually is not uncommon. It is not that many years down the road where the Energy Star certification becomes within reach. However, achieving this lofty annual energy reduction goal goes far beyond conventional energy retrofit projects.

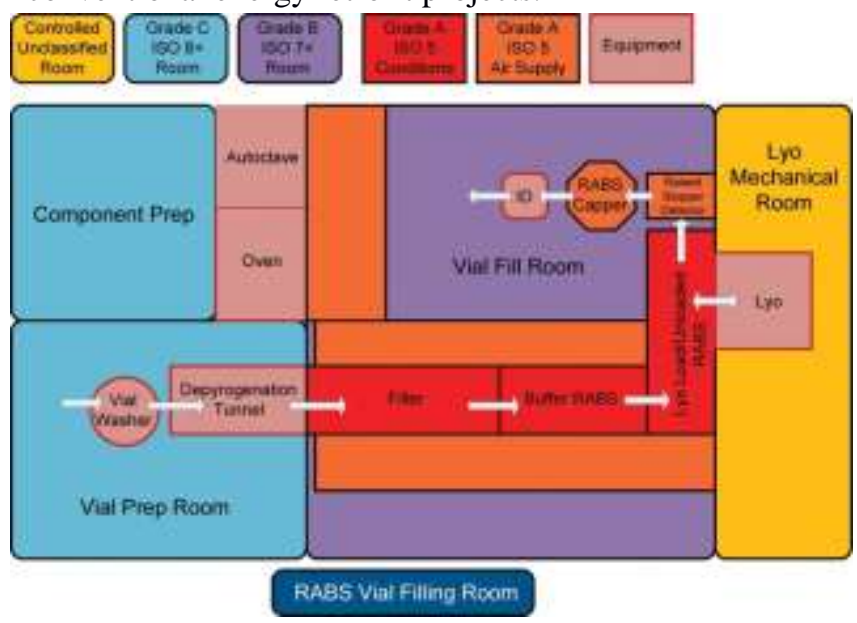

Fig 2- Vial filling suite utilizing a RABS.[8]

Based on the breakdown of pharmaceutical energy 


\section{International Journal of Innovations in Engineering and Science, www.ijies.net}

consumption by end use, it can be seen that traditionally common energy retrofits, such as lighting upgrades or motor replacements, do not make a significant impact. Lighting accounts for only 2 to $3 \%$ of overall energy usage in pharmaceutical manufacturing, even a 50\% reduction in lighting usage will barely yield significant savings as it pertains to overall facility EUI. Lighting retrofits certainly should not be discounted, especially since they are frequently subsidized by utility rebate programs, which enhance the overall project payback. However, in this industry, the energy is tied into the process itself and the supporting systems. For example, reducing the overall ventilation rate by only 5 to $10 \%$ in a pharmaceutical facility is the equivalent of eliminating the total lighting energy use in the facility. [9]

Significant reductions cannot be achieved unless the process itself is analysed, challenged, and optimized. Doing so is a task that requires significant expertise and knowledge regarding the regulatory and cGMP requirements of the manufacturing processes. Maintaining the environment to ensure product integrity and operating personnel protection and comfort are crucial factors that must be accommodated when making any changes to the process to save energy.

\subsection{Current Industry Trends}

In the past, energy expenditures have been a small portion of the total cost of goods in the pharmaceutical industry and thus were not overly a major concern. Over the last decade especially, with increased economic headwinds and rising energy costs, energy consumption is being much more scrutinized. Not only is there the impetus to lower overall internal costs, the industry is pushing toward more environ- mental stewardship and carbon reduction in light of largerglobal environmental trends. As a result, energy efficiency is being driven into the technologies used within the industry. For example, isolator technologies currently in production will utilize catalytic converters to break down Vaporous Hydrogen Peroxide (VHP) used during decontamination cycles into non-harmful constituents. This use of catalytic converters speeds up the aeration process and also negates the need for the HVAC system serving the isolator to go into purge mode (100\% once through) during aeration.

As the industry moves forward, energy consumption and cost will continue to be under downward pressure. Unlessa low cost, clean energy source is developed and industrialized, there is no near term end in sight. Many large pharmaceutical companies have long since implemented energy management programs, albeit to varying degrees of success. The challenge for some is now becoming how to continue to make improvements once all of the quick wins have been garnered while still remaining fiscally responsible. For others, mainly contract and generic manufacturers, efforts are ramping up to begin to manage and control energy costs. Where normal business practice has always been first cost sensitive, operating costs are quickly rising to the point where they can no longer be ignored.

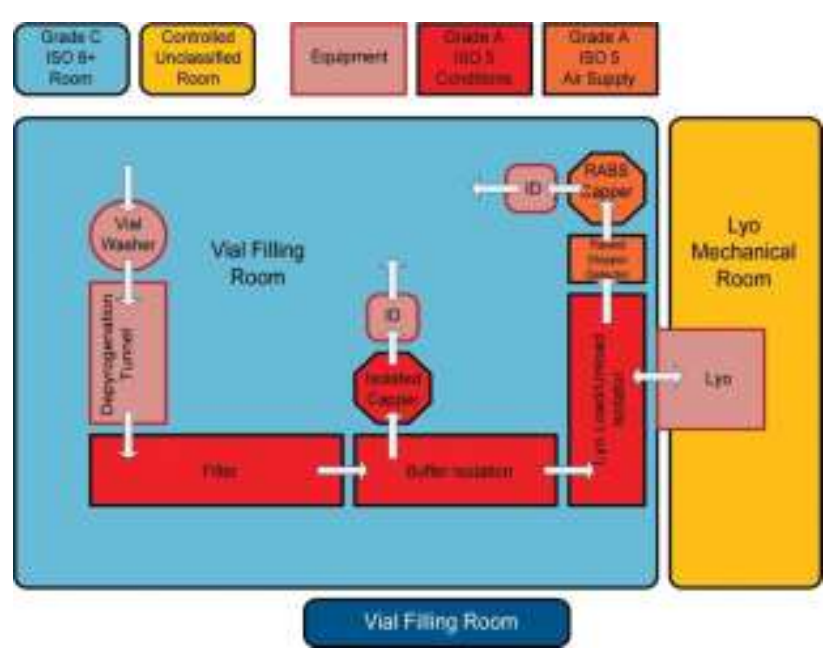

Fig 3-Vial filling suite using isolator technology.

\section{III -CONCLUSION}

Normalizing energy consumption across the pharmaceutical industry as a whole has proven difficult. Placing all of the operations that occur within the manufacturing processes into three separate categories for analysis may not always be specific enough for a true apple to apples comparison between facilities. Unlike in the commercial building sector, a pharmaceutical facility meeting the Energy Star performance threshold may have achieved the certification simply as a result of the process requirements driving the design of the facility without any significant introduction of energy management best practices. Similarly, a facility with many energy optimization strategies in place may ultimately be precluded from achieving certification based on the original factors considered during its design. However, benchmarking data using the EPI does prove valuable if the results are interpreted in the proper way and even more so if tracked over time.

Using the benchmarking tool to establish baseline energy performance and updating it on a regular basis will allow the user to monitor how well 


\section{International Journal of Innovations in Engineering and Science, www.ijies.net}

their facility is performing against its own baseline (which is key to validating the efficacy of the overall energy management program). While the energy performance range of a pharmaceutical manufacturing facility is often determined even before the facility is built, through consistent energy management best practices, the facility can certainly optimize the hand it was dealt. This not only is the environmentally responsible thing to do, it is now recognized good business practice.

\section{REFERENCES}

[1] EIA website, Commercial Buildings Energy Consumption Survey Page, http://www.eia.gov/consumption/ commercial, Accessed June 28, 2013

[2] US Department of Energy website, U.S. DOE Buildings Energy Data Book, http://buildingsdatabook.eren.doe. gov/docs/xls_pdf/3.1.4.pdf,Table 3.1.4, Accessed June 28, 2013.

[3] US Department of Energy website, U.S. DOE Buildings Energy Data Book, http://buildingsdatabook.eren.doe. gov/docs/xls_pdf/3.6.1.pdf, Table 3.6.1., Accessed June 28, 2013.

[4] Boyd, GA, Development of a Performance-based Industrial Energy Efficiency Indicator for Pharmaceutical Manufacturing Plants, http://www.energystar.gov/ia/ business/industry/in_focus/Pharmacuetical_EPI_documentation.pdf?01de-Oecc, Table 5, Accessed June 28, 2013.

[5] Thomas, P., "Will Pharma Wear the Energy Star," Pharma Manufacturing, 2006. http://www.pharmamanufacturing.com/articles/2006/046.html, Accessed June 28, 2013.

[6] Boyd, GA, Development of a Performance-based Industrial Energy Efficiency Indicator for Pharmaceutical Manufacturing Plants, Energy Star website.

http://www.energystar.gov/ia/business/industry/in_focu s/Phar- macuetical_EPI_documentation.pdf?01deOecc, Table 1., Accessed June 28, 2013.

[7] Boyd, GA., Development of a Performance-based Industrial Energy Efficiency Indicator for Pharmaceutical Manufacturing Plants, Energy Star website. $h t t p: / / w w w$. energystar.gov/ia/business/industry/in_focus/Pharmacuetical_EPI_documentation.pdf?01de-0ecc, Section 2.1 and 2.2, Accessed June 28, 2013.

[8] Kline SG, (June 5, 2013) "cGMP Aseptic Facility Design Based on Barrier Technology Presentation."

[9] Sartor D., 5 Big Hits in Laboratories, US Department of Energy website, http://fimsinfo.doe.gov/Work-
shop/2010/Sartor_Lab.pdf, Accessed June 28, 2013. 